ROMAN INGARDEN

DER STREIT UM DIE EXISTENZ DER WELT

II $/ 1$ 



\section{ROMAN INGARDEN}

\section{DER STREIT}

\section{UM DIE EXISTENZ \\ DER WELT \\ II/1}

FORMALONTOLOGIE

1. Teil

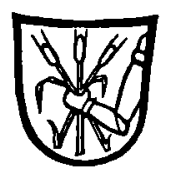

MAX NIEMEYER VERLAG TUBINGEN 1965 
Die polnische Fassung erschien in zwei Bänden unter dem Titel Spór o istnienie świata

1. Auflage: Polska Akademia Umiejętnosci, Krakau 1947/48

2. Auflage: Państwowe Wydawnictwo Naukowe, Warschau 1960/61

Die deutsche Ausgabe stellt eine neue Bearbeitung des Werkes dar. Band II wird bei gleicher Gliederung in zwei Halbbänden vorgelegt.

()

Max Niemeyer Verlag Tübingen 1965

Alle Rechte vorbehalten - Printed in Germany

Satz und Druds: Bücherdrudk Wenzlaff KG, Kempten/Allgäu

Einband: Großbuchbinderei Heinr. Koch, Tübingen 